Chirică R. ${ }^{1}$, Comșa G.I. ${ }^{2}$

\title{
Indirect effects of noise exposure on liver activity \\ - experimental case -
}

${ }^{1}$ Faculty of Medicine Constanta/Discipline Physiology

${ }^{2}$ Faculty of Medicine Constanta/Discipline ORL

\begin{abstract}
We live in a noisy world. We constantly undergoing in various types of noise that affect our quality of life. It is well known that noise is not only a problem but also a serious threat to health. The effects, that noise exposure has on health is a public serious problem, and is becoming more acute, which can occur at both, mentally and physically levels.
\end{abstract}

Keywords: health, exposure, noise, life

\section{Răzvan Chirică}

Str. Tulcea, nr. 10, Bl TM3 ap.23, Constanta $+40722361341$

razvan.chirica@yahoo.com

\section{Introduction}

Gamma-glutamyltransferase (GGT), also named gamma-glutamyltranspeptidase, is an enzyme present in liver and bile duct which is the most sensitive indicator of hepatobiliary diseases.

Due to a high negative predictive value for these diseases the measurement of gamma-GT is widely used to rule out a hepatic or biliary origin $[1,2]$.

Alkaline phosphatase (ALP), hydrolytic enzyme acting optimally at alkaline $\mathrm{pH}$, exists in blood in numerous distinct forms which originate mainly from bone and liver, but also from other tissues as kidney, placenta, testes, thymus, lung and tumors.

Physiological increases are found during bone growth in childhood and in pregnancy, while pathological increases are largely associated with hepatobiliary and bone diseases. 
In hepatobiliary disease they indicate obstruction of the bile ducts as in cholecystitis caused by gall stones, tumors or inflammation.

Elevated activities are also observed in infectious hepatitis. In bone diseases elevated ALP activities originate from increased osteoblastic activity as in Paget's disease, bone metastases and hyperparathyroidism $[3,4]$.

A stressor is a chemical or biological agent, environmental condition (elevated sound levels), external stimulus or an event that causes stress to biological organism [5].

Stressors have physical, chemical and mental responses inside of the body, and may also affect mental function and performance [6,7].

The aims of our studies are to determine how acute and chronic auditory stress change the values of ALP and GGT

\section{Materials and method}

Experimental animals used in our model were albino rats of Wistar line, males aged 14 weeks and weighing 200-220 g. that were cared for, in compliance with the rules of hygiene, food and accommodation required by Community legislation [8].

The experimental model consists of five groups, whose characteristics are:

- Control group (M) - animals in this group were not exposed to noise, serving as a reference for the experimental groups.

- Experimental group (E1) - animals in this group were exposed only once to noise $(38 \pm 2 \mathrm{~dB})$ for one hour, three minutes exposure, 3 minute break

- Experimental group (E2) - animals in this group were exposed only once to noise $(38 \pm 2 \mathrm{~dB})$ for 2 hours, 3 minutes exposure, 3 minute break

- Experimental group (E1-7) - animals in this group were exposed to a cycle of exposure to noise $(38 \pm 2 \mathrm{db})$ which lasted seven days, for an hour, 3 minutes exposure, 3 minute break.

- Experimental group (E2-7) - animals in this group were exposed to a cycle of exposure to noise $(38 \pm 2 \mathrm{db})$ which lasted 7 days, 2 hours, 3 minutes exposure, 3 minute break.

After noise exposure, blood samples were taken.

It was monitored the activity of the following parameters: Alkaline phosphatase (ALP), Gamma Glutamyltransferase (GGT), using a spectrophotometer CECIL CE 2012, 2000 Series, which is $1 \mathrm{~cm}$ tank.

Data were statistically analyzed using the usual methods, and calculate test " $t$ " of Student [9] was to determine the significance of difference between the averages that was compared.

\section{Results and Discussion}

In this study, animals were exposed to a noise source with a constant intensity of $38 \pm 2 \mathrm{db}$, but different time of period, depending on selected groups.

Sound intensity is located in the limit of audibility of Wistar rats, which can produce physiological changes. This intensity is equivalent to a value of $138 \pm 2 \mathrm{db}$, which is the threshold level of audibility to people.

The exposure of a biological organism to a noise source produces a change in the activity of the hypothalamic-pituitary axis resulting a change in the activity of each organ. Because of this, indirect changes occur in the liver function.

The indirect signs of liver damages are the changes in ALP secretion. This change is present in table number 1 representing the statistically modified values of the ALP with a value of $\mathrm{p} \leq 0.05$.

But, the single modified value of ALP does not indicate an indirect liver injury. According to the latest specialized studies, to show the indirect signs of liver damages, the values of GGT must be modified, also. 
Table I - The mean ALP values, for the control group and experimental group, after a single exposure for one hour or two hours, and after repeated exposure for 7 days

\begin{tabular}{|l|l|l|}
\hline ALP & $X$ & $\mathrm{P} \leq$ \\
\hline $\mathrm{M}$ & 73.52 & \\
\hline E1-7 & 66.59 & SI* \\
\hline E2-7 & 48.92 & 0.05 \\
\hline E1 & 20.59 & 0.01 \\
\hline E2 & 56.93 & 0.05 \\
\hline & & \\
\hline
\end{tabular}

(*statistically insignificant)

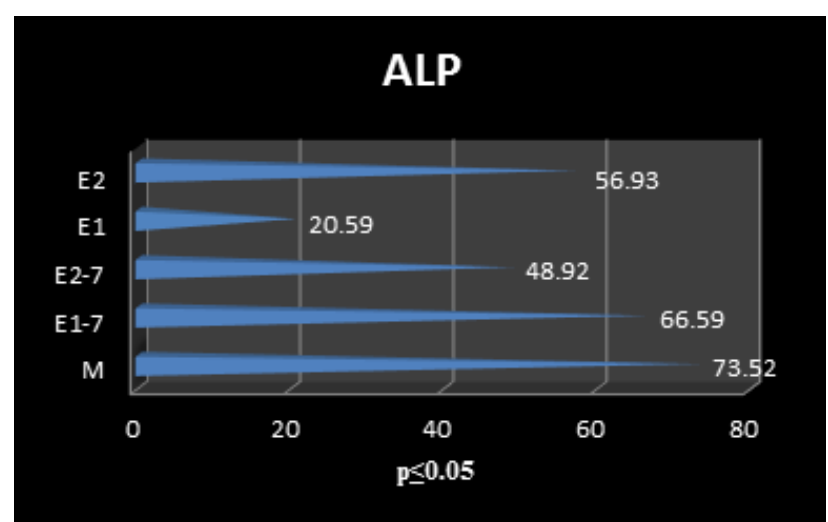

Figure 1 - Graphic variation of the values displayed in table no. 1

The graphic number 2 contains the statistically modified values of GGT, having a $p \leq 0.05$

Beside the fact that the serum transaminases represent the main indicators of the liver activity, it looks like ALP changes can suggest liver damage.

Table II - The mean GGT values, for the control group and experimental group, after a single exposure for one hour or two hours, and after repeated exposure for 7 days

\begin{tabular}{|l|l|l|}
\hline GGT & X & P $\leq$ \\
\hline M & 13.49 & \\
\hline E1-7 & 26.99 & 0.01 \\
\hline E2-7 & 15.74 & 0.05 \\
\hline E1 & 28.29 & 0.01 \\
\hline E2 & 29.95 & 0.01 \\
\hline
\end{tabular}

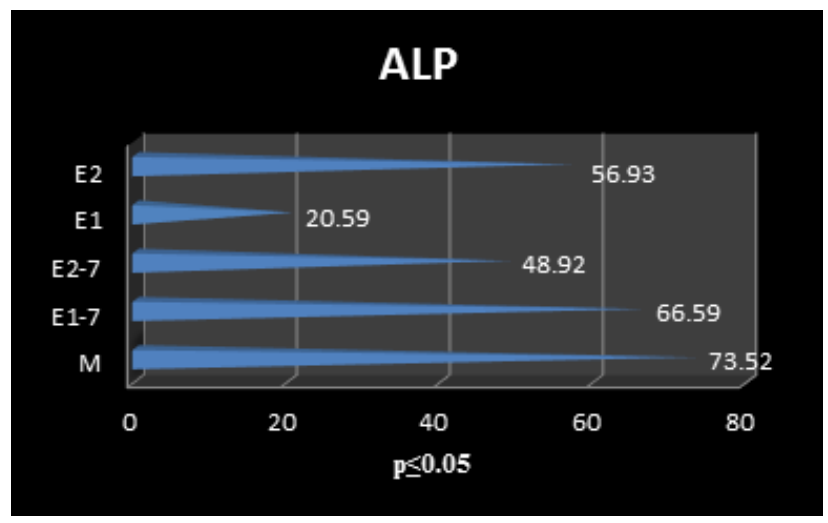

Figure 2 - Graphic variation of the values displayed in table II

\section{Conclusions}

1. Acoustic stress that we face every day is an important factor for liver and gallbladder damage.

2. We can consider that liver is suffering if the ALP values are changed, but only if is accompanied with changes of GGT values.

3. Due to the biological similarity between laboratory rats and humans, we can say that these changes may be present in humans.

4. Acute and chronic exposure of humans to daily noise can induce pathological changes of liver activity

\section{References}

1. Thomas, L. (1998) Clinical Laboratory Diagnostics. 1st ed. Frankfurt: TH-Books erlagsgesellschaft;.p.80-6.

2. Persijn, J.P. \& van der Silk W. (1976) A new method for the determination of gammaglutamyltransferase in serum. J Clin Chem Clin 
Biochem; 14:421-7.

3. Thomas, L. (1998) Clinical Laboratory Diagnostics. 1st ed. Frankfurt: TH-Books Verlagsgesellschaft;. p. 136-46.

4. Moss, D.W. \& Henderson, R. (1999) Clinical enzymology. In: Burtis CA, Ashwood ER. eds. Tietz textbook of clinical chemistry. 3rd ed. Philadelphia: W. B. Saunders Company. p. 617721.

5. Stressor". Pallipedia. Retrieved 2012-05-31.

6. National Research Council (2001). Musculoskeletal Disorders and the Workplace: Low Back and Upper Extremities. Washington, DC: The National Academies Press. National Academey Press. pp. 512. ISBN 0-309-07284-0.
7. National Research Council (1999). Work-Related Musculoskeletal Disorders: Report, Workshop Summary, and Workshop Papers. National Academy Press. pp. 240. ISBN 0-309-06397-3.

8. Ciudin, E. \& Marinescu, D. (1996) Animale de laborator, (vol. I) (pp 99-136), București, România, Ed. All

9. Senedecor, G.W. \& Cochran, WG. (1980) Statistical methods (7th ed.) (pp. 334-364) Ames, Iowa, Iowa State University Press. 